\title{
Constraints of The Implementation of Occupational Health and Safety Management System (OHSMS) in Construction Projects in Ternate City
}

\author{
Edward Rizky Ahadian * , Siti Qamaria Rumaru, Muhammad Darwis, Erwinsyah Tuhuteru \\ Civil Engineering, Faculty of Engineering, Khairun University, Ternate, Indonesia
}

\begin{abstract}
In a construction project there are various problems that occur, one of which is the problem regarding the occupational Occupational Health and Safety Management System (OHSMS) which must always be considered. The research location is located in the city of Ternate, North Maluku province. This study aims to determine which constraint variable has the most influence based on the perception of Occupational Health and Safety (OHS) experts. The method used is the Analytical Hierarchy Process method through the distribution of questionnaires and interviews with several construction companies. Based on the results of the AHP analysis, the rankings of the constraint variables are as follows: no evaluation related to OHS for workers in the field $(0.2312)$, low culture $(0.2277)$, no punishment for workers who do not carry out OHS in the field (0.1486).
\end{abstract}

Keywords: OHSMS, AHP, Construction Project

\section{Introduction}

The development and economic growth in Indonesia is now increasing rapidly, especially in the construction sector. The development carried out is not only focused on the ultimate goal of improving the economic welfare of the people in Indonesia. However, the development program must be supported by the implementation of Occupational Safety and Health (OHS) so that its implementation does not cause accidents and occupational diseases. The application of OHS culture itself is also an integral part of national development to increase Indonesia's productivity and competitiveness. As it is known that the aspects that are the parameters of the success of a project are quality, cost and work safety.

In 2020 Social Security Administrator Employment Ternate City reported that in the past two years, two construction companies had reported more than ten cases of project accidents. For this reason, it is necessary to note that the implementation of the Occupational Health and Safety Management System on construction projects in Ternate City is still experiencing many deviations from the provisions for implementing OHSMS, such as the lack of attention from the authorities to workers for mutual safety.

What is the most influential constraint variable in the implementation of OHSMS in Ternate City?

\section{Research purposes}

This research have purpose to know the most influential constraint variable in the implementation of OHSMS in Ternate City.

\section{Occupational Health and Safety Management System}

Occupational Health and Safety Management System, is part of the overall system which includes organizational structure, planning, responsibilities, implementation, implementation, achievement, assessment and maintenance of occupational safety and health policies in the context of controlling risks related to activities. work in order to create a safe, efficient and productive place (Minister of Manpower Regulation NO: PER. 05/MEN/2996). Thus, the Occupational Health and Safety management system is an effort to improve occupational safety and health in the workplace by involving elements of management, labor, working conditions and an integrated work environment in order to prevent and reduce accidents and occupational diseases.

\footnotetext{
* Corresponding author : edward.rizky@unkhair.ac.id
} 


\subsection{Benefits of implementing Occupational Health and Safety Management System}

Benefits of implementing Occupational Health and Safety Management System for industry according to [8] are:

a. Reduce work hours lost due to work accidents

b. Avoiding material and life losses due to work accidents

c. Creating an efficient and productive workplace because the workforce feels safe at work

d. Improve the market image of the company

e. Creating a harmonious relationship for employees and the company. Maintenance of machines and equipment is getting better, thus making the life of the tool longer.

\subsection{OHSMS Goals}

The purpose of implementing OHSMS is based on the Regulation of the Minister of Public Works No. 05/PRT/M/2014 are:

a. Improving the effectiveness of planned, measurable, structured and integrated occupational safety and health protection

b. Can prevent and reduce work accidents, and occupational diseases

c. Creating a safe, comfortable and efficient workplace to encourage productivity.

\subsection{Obstacles in implementing OHSMS}

According to Government Regulation No. 50 of 2012. The Occupational Health and Safety Management System, hereinafter referred to as OHSMS, is part of the company's overall management system in controlling risks related to work activities in order to create a safe, efficient, and productive workplace.

Generally, states that the causes of work accidents in construction can be grouped into four factors, namely the worker's own factor, the construction method factor, the equipment factor and the management factor [3]. Even though humans have been careful, but if the environment is not supportive (unsafe), then accidents can occur. happened too. So should it be. Therefore, it is necessary to have a guide on how to work that meets the principles of work safety.

Not a few of the companies that still do not provide good and correct OHSMS services to their employees. Though it is very important for the future of the company as well. This can be caused by the following factors:

a. Company management gives low priority to the OHS program in the company program

b. Lack of knowledge about OHS from both the company and its employees.

c. Limited capital in providing OHS services

d. Weak government oversight of OHS

Table 1. Pairwise comparison matrix.

\begin{tabular}{|c|c|c|c|c|}
\hline & 1st Criterion & 2nd Criterion & $\ldots$. & nth criterion \\
\hline 1st Criterion & & & & \\
\hline 2nd Criterion & & & & \\
\hline$\ldots$ & & & & \\
\hline nth criterion & & & & \\
\hline
\end{tabular}

Due to the OHS program which is very important to ensure the safety and health of the company's employees, of course the company will have a bad impact if the company does not provide OHS services to its employees, such as:

a. The occurrence of injury can even cause death to workers

b. Cause disease

c. Giving loss

d. The work process in the company is hampered

\subsection{Analytic Hierarchy Process Method}

The Analytical Hierarchy Process (AHP) method is one of the decision-making models developed by Thomas L. Saaty to overcome complex multi-factor or multicriteria problems into a hierarchy. Hierarchy is defined as a representation of a complex problem in a multi-level structure where the first level is the goal followed by the level of factors, criteria, sub-criteria and so on down to the last level of alternatives. With a hierarchy, a complex problem can be broken down into groups which are then arranged into a hierarchical form so that the problem will appear more structured and systematic. In general, by using AHP, the resulting priorities are theoretically consistent, logical, transparent and participatory.

AHP is often used as a problem-solving method compared to other methods for the following reasons:

a. A hierarchical structure, as a consequence of the selected criteria to the deepest sub-criteria.

b. Take into account the validity up to the tolerance limit for the inconsistency of various criteria and alternatives chosen by the decision maker.

c. Take into account the durability of the decisionmaking sensitivity analysis output.

In general, decision making with the AHP method is based on the following steps:

a. Define the problem and determine the desired solution

b. Create a hierarchical structure that begins with general goals, followed by criteria and alternative choices that you want to rank.

c. Form a pairwise comparison matrix that describes the relative contribution or influence of each element to each goal or criterion that is at the level above. Comparisons are made based on the choice or judgment of the decision maker by assessing the level of importance of an element compared to other elements. 
d. Normalizing the data is by dividing the value of each element in the matrix. In the AHP method, the definition of the comparison of various elements is in the form of a number scale from 1 to 9 which shows the level of importance of each element to other elements. The definition of each scale is as shown in the table below.

Table 2. Pairwise comparison matrix.

\begin{tabular}{|cl|}
\hline Level of Interest & \\
1 & Equally important \\
3 & A little more important \\
5 & Obviously more important \\
7 & Very clearly more important \\
9 & Definitely/absolutely more important (extreme importance) \\
$2,4,6,8$ & If in doubt between two adjacent values \\
$1 /(1-9)$ & The inverse of the importance level on a scale of 1-9 \\
\hline
\end{tabular}

e. Calculates the priority value of the criteria. After getting the weights, the weight values are then multiplied by the paired matrix obtained at the beginning. The largest product is the most important criterion. Before finding the value of the weight vector, normalization of the pairwise comparison matrix elements is carried out. Normalization is done by dividing each element by the number of each column. The value of the weight vector is determined by averaging, adding up each row and then dividing by the number of existing criteria.

f. Test the consistency of the hierarchy. If it does not meet the $\mathrm{CR}<0,100$; then the assessment must be repeated.

The steps in consistency testing are:

- Multiplying the weight value that has been obtained by the paired matrix obtained at the beginning.

- Determine the value. The value is obtained by the formula: $\alpha$ maks $\alpha m a k s$ $\lambda m a k s=\mathrm{x}(+++\ldots+) \frac{1}{n} \frac{A 1}{W 1} \frac{A 2}{W 2} \frac{A 3}{W 3} \frac{A n}{W n}$

With $\mathrm{n}=$ the number of criteria, $\mathrm{A}=$ the product of the weighted values with the paired matrix of each criterion. $\mathrm{W}=$ eigenvalue in row format.

- Calculate the Consistency Index (CI) by subtracting the value from the number of criteria. The result is divided by the number of criteria. $\alpha$ maks

$$
C I=\frac{(\lambda m a k s \quad)}{n-1}
$$

- Calculate Consistency Ratio (CR) by dividing CI by RI value.

$$
C R=\frac{C I}{R I}
$$

With $\mathrm{CI}=$ Consistency Index value and RI $=$ Random Index value $\mathrm{CR}$ value to determine whether the data is consistent or not, provided that:

$\mathrm{CR}<0.1$ (data consistent)

$\mathrm{CR}>0.1$ (data inconsistent).

Table 3. Pairwise comparison matrix.

\begin{tabular}{|c|c|c|c|c|c|c|c|c|c|c|}
\hline Order matrix & 1 & 2 & 3 & 4 & 5 & 6 & 7 & 8 & 9 & 10 \\
\hline RI & 0 & 0 & 0.58 & 0.90 & 1.12 & 1.24 & 1.32 & 1.41 & 1.45 & 1.49 \\
\hline
\end{tabular}

- Check the value of the CR, if the CR is less than 0.1 then the results can be said to be consistent. Otherwise, the paired matrix must be repeated to be created.

- However, if the CR value is less than $10 \%$, then the inconsistency is still acceptable.

\section{Research Variables Obstacles to the Implementation of SMK3}

Based on previous research journals and several surveys, several variables can be taken, namely:

a. Lack of training on Occupational Safety and Health

b. There is no budget regarding $\mathrm{K} 3$ in the construction project

c. There are no sanctions for workers who do not implement $\mathrm{K} 3$

d. There is no special unit that deals with $\mathrm{K} 3$ e. Low culture and discipline

f. Lack of knowledge related to $\mathrm{K} 3$

g. There is no evaluation related to $\mathrm{K} 3$ for workers in the field.

\section{Population and Respondents}

The previously mentioned variables were then used to compile a questionnaire for data collection through surveys. The population used in this study are objects in the city of Ternate taken through the GAPENSI, GAPEKNAS, GAPEKSINDO agencies. With a sample of 18 .

Respondents are people who are asked to provide information about a fact or opinion. The planned respondents are 10 people with the following respondent criteria: 
a. Bachelor or Diploma education or equivalent with the following conditions:

- Bachelor or Diploma with work experience in the field of OHS at least 2 years.

- Have a certificate of expertise in the field of Construction OHS.

a. Medium (M1 and M2) and large (L1 and L2) qualified contractors with a minimum of 2 years work experience.

\section{Results and Discussion}

\subsection{Respondent's description}

Respondents in this study are experts in several construction companies who have OHS expert certificates and have work experience in the construction field for more than 5 years. The number of respondents targeted by the researcher was 28 companies, but the addresses of 10 companies were not found so the researchers only took 18 companies, then the questionnaires that could be collected were 10 companies. For 8 respondents in companies that could not be reached because at the time of my research as a researcher I experienced difficulties, namely the length of response from getting the intended respondent to fill out the research questionnaire. For this reason, the researcher took 10 respondents who had been achieved for this study, which had reached more than $50 \%$ of the total questionnaires.

\subsection{AHP analysis method}

\section{a. Hierarchy}

After the problem is defined, the next step is to break the whole problem into its elements. Solving is also carried out on the elements until it is impossible to do further solving to get accurate results. In the AHP method, the criteria are usually arranged in a hierarchical form. The criteria that have been prepared by the researcher are then rated by the respondents according to the provisions of this method

Table 4. Research variable

\begin{tabular}{|c|l|}
\hline Variable & Information \\
\hline V1 & Lack of training on OHS \\
\hline V2 & Absence of OHS budget in construction projects \\
\hline V3 & There are no sanctions for workers who do not implement OHS \\
\hline V4 & There is no special unit that takes care of OHS \\
\hline V5 & Low discipline culture \\
\hline V6 & Lack of knowledge related to OHS \\
\hline V7 & There is no evaluation related to OHS in the field \\
\hline
\end{tabular}

\section{b. Create a pairwise comparison matrix.}

Paired matrix table that describes the relative contribution of the influence of each element on each criterion goal at the level above it. At this stage a comparative assessment is carried out based on the perceptions of the intended contractor or respondent.

Table 5. Initial matrix of respondents A.

\begin{tabular}{|c|c|c|c|c|c|c|c|}
\hline Variable & V1 & V2 & V3 & V4 & V5 & V6 & V7 \\
\hline V1 & 1 & 5 & $1 / 3$ & $1 / 5$ & $1 / 7$ & 5 & $1 / 5$ \\
\hline V2 & $1 / 5$ & 1 & $1 / 3$ & $1 / 5$ & $1 / 9$ & $1 / 3$ & $1 / 3$ \\
\hline V3 & 3 & 3 & 1 & $1 / 3$ & $1 / 5$ & 2 & $1 / 3$ \\
\hline V4 & 5 & 5 & 3 & 1 & $1 / 3$ & 3 & $1 / 3$ \\
\hline V5 & 7 & 9 & 5 & 3 & 1 & 5 & $1 / 3$ \\
\hline V6 & $1 / 5$ & 3 & $1 / 2$ & $1 / 3$ & $1 / 5$ & 1 & $1 / 3$ \\
\hline V7 & 5 & 3 & 3 & 3 & 3 & 3 & 1 \\
\hline
\end{tabular}

Next, perform pairwise comparisons in table 6 Number 1 in column V1 row V1 illustrates the same level of importance between the variable lack of training on OHS and lack of training on OHS, while number 3 in column V2 row V3 shows the variable that there is no sanctions for workers who do not carry out OHS is slightly more important than the variable. there is no budget regarding OHS in construction projects. Furthermore, it can be seen the level of importance between 
variables by looking at the numbers listed in each column and row.

Table 6. Pairwise comparison matrix A

\begin{tabular}{|c|c|c|c|c|c|c|c|}
\hline Variable & V1 & V2 & V3 & V4 & V5 & V6 & V7 \\
\hline V1 & 1,000 & 5,000 & 0.333 & 0.200 & 0.143 & 5,000 & 0.200 \\
\hline V2 & 0.200 & 1,000 & 0.333 & 0.200 & 0.111 & 0.333 & 0.333 \\
\hline V3 & 3,000 & 3,000 & 1,000 & 0.333 & 0.200 & 2,000 & 0.333 \\
\hline V4 & 5,000 & 5,000 & 3,000 & 1,000 & 0.333 & 3,000 & 0.333 \\
\hline V5 & 7,000 & 9,000 & 5,000 & 3,000 & 1,000 & 5,000 & 0.333 \\
\hline V6 & 0.200 & 3,000 & 0.500 & 0.333 & 0.200 & 1,000 & 0.333 \\
\hline V7 & 5,000 & 3,000 & 3,000 & 3,000 & 3,000 & 3,000 & 1,000 \\
\hline
\end{tabular}

The number 0.200 in column V1 row V2 is the result of calculating $1 /$ value in column V2 row V1 (5). Or it can be written $1 / 5$ which the result is 0.200 .

\section{c. Synthesis}

To obtain overall priority, the considerations for pairwise comparisons need to be synthesized. In this step the things that need to be done are:

Respondent matrix A
- Sum the values of each column in the matrix.

- Divide each value from the column by the corresponding column total to obtain a normalized matrix.

- Add up the values of each row and divide by the number of elements to get the average value.

The results are displayed in the following matrix:

Table 7. Number of columns V1 - V7

\begin{tabular}{|c|c|c|c|c|c|c|c|}
\hline Variable & V1 & V2 & V3 & V4 & V5 & V6 & V7 \\
\hline Amount & 21,400 & 29,000 & 13.167 & 8067 & 4.987 & 19,333 & 2.867 \\
\hline
\end{tabular}

Table 8. Table of eigenvalues

\begin{tabular}{|c|c|c|c|c|c|c|c|}
\hline Variable & V1 & V2 & V3 & V4 & V5 & V6 & V7 \\
\hline V1 & 0.047 & 0.172 & 0.025 & 0.025 & 0.029 & 0.259 & 0.070 \\
\hline V2 & 0.009 & 0.034 & 0.025 & 0.025 & 0.022 & 0.017 & 0.116 \\
\hline V3 & 0.140 & 0.103 & 0.076 & 0.041 & 0.040 & 0.103 & 0.116 \\
\hline V4 & 0.234 & 0.172 & 0.228 & 0.124 & 0.067 & 0.155 & 0.116 \\
\hline V5 & 0.327 & 0.310 & 0.380 & 0.372 & 0.201 & 0.259 & 0.116 \\
\hline V6 & 0.009 & 0.103 & 0.038 & 0.041 & 0.040 & 0.052 & 0.116 \\
\hline V7 & 0.234 & 0.103 & 0.228 & 0.372 & 0.602 & 0.155 & 0.349 \\
\hline
\end{tabular}

The eigenvalues are obtained by dividing each value from the column by the total column in question.

Table 9. Number of rows and average value of $\mathrm{V} 1-\mathrm{V} 7$

\begin{tabular}{|c|c|c|c|c|c|c|c|}
\hline Variable & V1 & V2 & V3 & V4 & V5 & V6 & V7 \\
\hline Amount & 0.626 & 0.250 & 0.621 & 1.096 & 1,965 & 0.400 & 2.042 \\
\hline Average & 0.089 & 0.036 & 0.089 & 0.157 & 0.281 & 0.057 & 0.292 \\
\hline
\end{tabular}

The number of rows is obtained by dividing each value of the row by the total row in question. While the average value is obtained by dividing the number by the number of variables, if the average value obtained is not equal to zero, then an error is identified in the calculation. And from the average value can also be known the level of importance of each variable. The greater the value of a variable, it determines the level of importance or influence on the implementation of OHSMS in the city of Ternate. Likewise, so on. From the results of the AHP analysis on respondent A, the most influential variable in the obstacles to implementing SMK3 in the city of Ternate is variable 7 (there is no evaluation related to OHS in the field) with a weight of 0.292 .

\subsection{Calculating value Consistency Index and Consistency Ratio.}

a. Consistency Index

(Respondent A)

$\mathrm{CI}=(\lambda \max -\mathrm{n}) /(\mathrm{n}-1)$

$\mathrm{n}=7$ 
$\max =\mathrm{x} \frac{1}{n}\left(\frac{A 1}{W 1}+\frac{A 2}{W 2}+\frac{A 3}{W 3}+\cdots+\frac{A n}{W n}\right)$

$\mathrm{CI}=(\lambda \max -\mathrm{n}) /(\mathrm{n}-1)=>\mathrm{CI}=0.262$

b. Consistency Ratio
$\mathrm{CI}=0.262 . \mathrm{RI}=1.32($ can be seen in table 10

Random Index)

$\mathrm{CI} / \mathrm{RI}=>\mathrm{CR}=0.198 \%$

Table 10. Calculation Results of Consistency Ratio Value

\begin{tabular}{|l|c|c|c|c|c|}
\hline Perception & Max & $\mathrm{n}$ & CI & RI & CR \\
\hline Respondent A & 8,570 & 7 & 0.262 & 1.32 & $0.198 \%$ \\
\hline Respondent B & 8,459 & 7 & 0.243 & 1.32 & $0.184 \%$ \\
\hline Respondent C & 11,220 & 7 & 0.730 & 1.32 & $0.533 \%$ \\
\hline Respondent D & 9.022 & 7 & 0.337 & 1.32 & $0.255 \%$ \\
\hline Respondent E & 8,359 & 7 & 0.227 & 1.32 & $0.172 \%$ \\
\hline Respondent F & 9,247 & 7 & 0.374 & 1.32 & $0.284 \%$ \\
\hline Respondent G & 12.849 & 7 & 0.975 & 1.32 & $0.739 \%$ \\
\hline Respondent H & 9,258 & 7 & 0.376 & 1.32 & $0.285 \%$ \\
\hline Respondent I & 9,450 & 7 & 0.408 & 1.32 & $0.309 \%$ \\
\hline Respondent J & 12,512 & 7 & 0.919 & 1.32 & $0.696 \%$ \\
\hline
\end{tabular}

The priority results show the rank or priority value given by each respondent to the seven research variables.

Table 11. Priority results for each variable based on respondents' perceptions.

\begin{tabular}{|l|c|c|c|c|c|c|c|}
\hline Priority & $\mathrm{V} 1$ & $\mathrm{~V} 2$ & $\mathrm{~V} 3$ & $\mathrm{~V} 4$ & $\mathrm{~V} 5$ & $\mathrm{~V} 6$ & $\mathrm{~V} 7$ \\
\hline Respondent A & 0.089 & 0.036 & 0.089 & 0.157 & 0.281 & 0.057 & 0.292 \\
\hline Respondent B & 0.026 & 0.049 & 0.116 & 0.071 & 0.285 & 0.217 & 0.235 \\
\hline Respondent C & 0.152 & 0.089 & 0.179 & 0.03 & 0.125 & 0.189 & 0.237 \\
\hline Respondent D & 0.063 & 0.023 & 0.099 & 0.239 & 0.346 & 0.052 & 0.178 \\
\hline Respondent E & 0.061 & 0.028 & 0.13 & 0.14 & 0.35 & 0.079 & 0.213 \\
\hline Respondent F & 0.082 & 0.045 & 0.195 & 0.163 & 0.197 & 0.036 & 0.283 \\
\hline Respondent G & 0.072 & 0.055 & 0.213 & 0.109 & 0.215 & 0.196 & 0.139 \\
\hline Respondent H & 0.089 & 0.048 & 0.15 & 0.158 & 0.137 & 0.045 & 0.373 \\
\hline Respondent I & 0.105 & 0.021 & 0.114 & 0.271 & 0.211 & 0.036 & 0.242 \\
\hline Respondent J & 0.112 & 0.104 & 0.201 & 0.114 & 0.13 & 0.218 & 0.12 \\
\hline Average & 0.0851 & 0.0498 & 0.1486 & 0.1452 & 0.2277 & 0.1125 & 0.2312 \\
\hline
\end{tabular}

Table 12. Variable Rank

\begin{tabular}{|c|c|c|c|}
\hline Rating & Priority Value & $\begin{array}{c}\text { Variable } \\
\text { Code }\end{array}$ & Variable Name \\
\hline 1 & 0.2312 & V7 & There is no evaluation related to OHS in the field. \\
\hline 2 & 0.2277 & V5 & Low culture and discipline. \\
\hline 3 & 0.1486 & V3 & There are no sanctions for workers who do not \\
implement OHS.
\end{tabular}

Based on the priority values above, that the main obstacle in implementing OHSMS is the absence of evaluation related to OHS for workers in the field, followed by the constraint variable, the low culture of discipline, the absence of sanctions being the constraint variable in the third position, the absence of a special unit that deals with OHS knowledge related to OHS, then there is a lack of training on OHS, the last is the second variable or the absence of a budget regarding OHS in the construction project. From several interviews between researchers and respondents that one of the things that is difficult to apply to workers in the field is related to the discipline of workers towards OHS equipment which has then been prepared such as helmets, vests and so on, because many of the workers feel they are used to working without these tools, especially the workers who come from North Maluku itself. Meanwhile, if those employed are workers outside of North Maluku, then they will tend to obey the existing rules. It was said by one respondent that most 
workers from outside North Maluku obeyed these rules because they were afraid of being fired if they violated them. Meanwhile, workers in North Maluku themselves mostly do not comply with applicable regulations but are rarely reprimanded by supervisors or contractors in the field. Respondents also said that after being reprimanded especially with a stern warning or until dismissed, then it is feared that something will then happen to the contractors or supervisors such as suddenly dying and others. He also added that the reason for the cloth was that it was difficult to find replacement workers. For the budget itself, it is not so much a major constraint as some previous studies related to this problem because according to information received during interviews with respondents that in 2018 there was already a special budget allocation for the implementation of OHS considering the importance of implementing OHS for both workers and parties. company and related parties. However, several other respondents acknowledged that the implementation of OHS in projects in the city of Ternate has been satisfactory. He also added that the reason for the cloth was that it was difficult to find replacement workers. For the budget itself, it is not so much a major constraint as some previous studies related to this problem because according to information received during interviews with respondents that in 2018 there was already a special budget allocation for the implementation of OHS considering the importance of implementing OHS for both workers and parties. company and related parties. However, several other respondents acknowledged that the implementation of OHS in projects in the city of Ternate was satisfactory. He also added that the reason for the cloth was that it was difficult to find replacement workers. For the budget itself, it is not so much a major constraint as some previous studies related to this problem because according to information received during interviews with respondents that in 2018 there was already a special budget allocation for the implementation of OHS considering the importance of implementing OHS for both workers and parties. company and related parties. However, several other respondents acknowledged that the implementation of OHS in projects in the city of Ternate was satisfactory. For the budget itself, it is not so much a major constraint as some previous studies related to this problem because according to information received during interviews with respondents that in 2018 there was already a special budget allocation for the implementation of OHS considering the importance of implementing OHS for both workers and parties. company and related parties. However, several other respondents acknowledged that the implementation of OHS in projects in the city of Ternate was satisfactory. For the budget itself, it is not so much a major constraint as some previous studies related to this problem because according to information received during interviews with respondents that in 2018 there was already a special budget allocation for the implementation of OHS considering the importance of implementing OHS for both workers and parties. company and related parties. However, several other respondents acknowledged that the implementation of
OHS in projects in the city of Ternate has been satisfactory.

\section{Conclusion}

Based on the results of the research and data processing above, it can be concluded that the application of OHSMS in the city of Ternate. Constraints to the implementation of OHS produced successively starting from the top priority are the absence of evaluations related to OHS for workers in the field, followed by the constraint variable, the low culture of discipline, the absence of sanctions for those who do not implement OHS in the field, the absence of a special unit that deals with about OHS, lack of knowledge related to OHS, lack of training on OHS, the last is the absence of a budget regarding OHS in the construction project of .

\section{References}

[1] Awuy, T., Pratasis, PAK and Mangare, JB (2017) Inhibiting Factors in the Implementation of OHS Management Systems in Construction Projects in Manado City, Journal of Civil Statistics.

[2] Dyahrini, W. (2006) Occupational Health and Safety Management System, Permenaker Number 5.

[3] rvianto, WI (2002) Construction Project Management, First Edition, Salemba Empat, p. 2002.

[4] Leliana, I. and Latief, AM (2016) 'The Influence of Company Work Climate and Training Design on Employee Work Motivation of PT PLN (Persero) UBS P3B Java Bali', Perspective Journal.

[5] Pangkey, F., Malingkas, GY and Walangitan, DOR (2012) Application of Occupational Health and Safety Management System (Smk3) in Construction Projects in Indonesia (Case Study: Dr. Ir. Soekarno-Manado Bridge Construction)', Scientific Journal of Media Engineering .

[6] Pratasis, P. (2011) 'Strategies for Improving the Implementation of Occupational Safety and Health in Companies JasPangkey, F., Malingkas, GY and Walangitan, DOR (2012) Implementation of Occupational Health and Safety Management Systems (SMK3) in Construction Projects in Indonesia (Stud', Techno).

[7] Saaty, TL (2002) 'Decision making with the Analytic Hierarchy Process', Scientia Iranica. Inderscience Publishers.

[8] Sucipto, CD (2014) 'Occupational Health and Safety', Yogyakarta: Gosyen Publishing.

[9] Sulistyanto, E. and Sulistyo, B. (2018) 'Application of Occupational Health and Safety Management Systems at the Light Vehicle Engineering Workshop at SMK Negeri 2 Yogyakarta Saaty, TL (2008) "Decision making with the analytic hierarchy process", International journal of services sciences. Inderscience Publis', Journal of Automotive Engineering Education.

[10] Suma'mur, PK (1985) 'Occupational Diseases'. Hyperkes. 
[11] Tasliman, HA (1993) 'Occupational Safety and Health (Teaching Materials)', Yogyakarta: UNY.

[12] Waluyo, R. and Aditama, S. (2017) 'The Effect of Resources Leveling on Manpower Allocation in Construction Projects', Scientific Journal of Civil Engineering. 